\title{
Hakikatin Yitimi Olarak Post-Truth: Bir Kavramsallaştırma Denemesi
}

\author{
AHMET GÜVEN* \\ aguven@bandirma.edu.tr \\ ORCID ID: 0000-0002-2452-2992
}

Öz: İletişim araçlarının yapısındaki büyük dönüşüm, etik tartışmaları da beraberinde getirmiştir. Son yıllarda sıklıkla gündeme gelmeye başlayan post-truth kavramı bu tartışmaların odağında yer almaktadır. Oxford Dictionary’nin yaptı̆̆ tanıma göre kamuoyunun nesnel olgulardan ziyade kişisel duygu ve inançlar tarafindan belirlenmesi anlamına gelen post-truth, akademik çalışmaların da üzerinde durduğu bir kavram haline gelmiştir. Daha çok yalan haber, gerçekliğin çarpıtılması ve bu yolla kamuoyunun irrasyonel tercihler yapması çerçevesinde ele alınan kavram bu haliyle problemli görünmektedir.

Bu çalışmanın temel iddiası post-truth kavramının, yalan ve çarpıtma haberlerle kamuoyunun yönlendirilmesi şeklinde tanımlanamayacağıdır. Bu bağlamda yapılan kavramsal tartışma çalışmanın yöntemini de teşkil etmektedir. İletişim araçlarının (medium) çağın hakikat algısını belirlediği iddiasında olan teknolojik determinist yaklaşım tartışmanın teorik zemini oluşturmaktadır. Tartışmadan elde edilen sonuç ise postmodernizmin hakikatin varlığını reddeden tavrinın elektronik medyanin yapisindan kaynaklandiğı ve post-truth kavraminın bu bağlamda hakikatin çarpıtılması olarak değil hakikat arzusunu yitimi olarak tanımlanması gerektiğidir.

Anahtar Kelimeler: Post-truth, Postmodernizm, Teknolojik determinizm, Sosyal medya, Hakikatin yitimi.

\section{Giriș}

Post-truth kavramı, 2004 yılında Ralph Keyes tarafından kullanılmış olsa da 2016 yılında Oxford Dictionary'nin yılın kelimesi olarak post-truth kelimesini seçmesinin ardından oldukça popüler hale gelmiştir. Post-truth üzerine yapılan çalışmalar hızla artmaya ve bu yeni kavramı bir çağın niteleyicisi olarak kullanma eğilimi rağbet görmeye başlamıştır. Genellikle post-truth kelimesini tanımlamak için Oxford

* Dr. Öğr. Üyesi, Bandırma Onyedi Eylül Üniversitesi, Medya ve İletişim Bölümü. 
Dictionary’nin verdiği tanım kabul edilirken bu tanım çerçevesinde kavram, çeşitli parametrelere uygulanacak bir paradigma gibi ele alınmaktadır. Ne var ki post-truth kavramının ne olduğu sorusu üzerine henüz yeterince tartışma yapılmış ve kavramsal bir çerçeve oluşturulmuş değildir. Bu çerçeve eksikliği, kavramın Türkçe’ye çevrilme güçlüğünden metinlerin anakronik ifade sorunlarına düşmelerine kadar geniş bir muğlaklı̆̆

Post-truth kavramı ABD seçimlerinde Donald Trump’ın başkan seçilmesi ve İngiltere'nin Brexit referandumu bağlamında tartışılmaya başlanmıştır. Akademik çalışmaların çoğu popülist söylemin "gerçekliğe" üstün gelmesi ve dolayısıyla irrasyonel olanın rasyonel olandan daha fazla taraftar bulmasının olumsuzluğu üzerinedir. ${ }^{1}$ Trump'ın seçim öncesi söylemlerinde yer alan Meksika sınırına duvar örmek gibi vaatleri, yabancı düşmanlığı üzerine kurulmuş söylemleri post-truth siyaset olarak kabul edilmektedir. ${ }^{2}$ Benzer şekilde İngiltere’nin Avrupa Birliği’nden ayrılmak için yaptığı referandumda ayrılıkçı kanadın ortaya koyduğu söylemin gerçeklikten uzak olduğu fakat buna rağmen ayrılıkçıların sandıkta galip gelmesinin gerçeklikten kopuk bir siyasete yol açtı̆̆ı tartışmaları yapılmaktadır. Buradaki iddia gerçek bilginin yozlaştığı ve artan popülist söylemin hakikatin önemini yok ettiği yönündedir. ${ }^{3}$ Her ne kadar tanımda yer almasa da kavramın sosyal medya ile ilişkisi aşikardır. Zaten söz konusu irrasyonel kararların ortaya çıkmasında sosyal medyanın başat rolü oynadığı tüm akademik çalışmaların ortak noktasıdır. Elbette Facebook skandalı ve Cambridge Analytica davası sosyal medyanın siyasal bir manipülasyon aracı olarak kullanıldığının önemli bir göstergesidir. Bu skandalda büyük veri (big data), yalan haber (fake news) ve yankı fanusları (eco chambers) kavramları ön plana çıkmıştır. ${ }^{4} 2014$ yılında ABD seçmen profilini araştırmak amacıyla Aleksandr Kogan tarafından geliştirilen bir anket Facebook üzerinden kullanıcılara ulaştırılmıştır. Anketi cevaplayan tüm kullanıcılar Facebook profil bilgilerinin uygulama ile paylaşılmasını kabul etmişlerdir. Böylece ilk aşamada 270 bin kullanıcının (bu kullanıcıların Facebook arkadaşları da dahil edildiğinde) nihai olarak yaklaşık 50 milyon kullanıcın profil bilgilerine erişim sağlandıktan sonra ortaya çıkan bu büyük veri (big data) Cambridge Analytica isimli veri toplama ve analiz şirketine satılmıştır. Cambridge Analytica'nın seçmen profillerinden meydana gelen bu büyük veriyi işleyerek ABD seçmenlerinin Donald Trump’a oy vermelerini sağlayacak şekilde bireysel mesajlar gönderdikleri iddia edilmektedir. Channel 4 muhabirlerinin gizli kamera kullanarak şirketin yöneticisi olan Alexander Nix ile yaptıkları görüşmelerde Nix bu iddiayı doğrulamakta hatta seçmenleri yönlendirmek için yalan haberleri nasıl servis ettiklerini anlatmaktadır. ${ }^{5}$ Cambridge Analytica’nın farklı ülkelerde de

\footnotetext{
1 Volkan Şimşek, “Post-truth ve Yeni Medya: Sosyal Medya Grupları Üzerinden Bir İnceleme”, Global Media Journal TR Edition, 8/16 (2018); Kezban Karagöz, "Post-truth Çağında Yayıncılığın Geleceği”, TRT Akademi Dergsisi, $3 / 6$ (2018); Mesut Özcan, "Öznenin Ölümü: Post-truth Çağında Güvenlik ve Türkiye”, İNSAMER, (2018); Işıl Z. T. İpek, “Risk Toplumunda Seçimler”, Sosyoekonomi, 26/36 (2018).

2 Şimşek, "Post-truth ve Yeni Medya: Sosyal Medya Grupları Üzerinden Bir İnceleme”, s.2.

3 Şimşek, “Post-truth ve Yeni Medya: Sosyal Medya Grupları Üzerinden Bir İnceleme”, s.3.

4 Orhan Şener, "Filtre Balonu Patlıyor mu: Guardian'dan Sağcı Yazar Açılımı", erişim 20 Şubat 2017, https:// journo.com.tr/filtre-balonu-patliyor-mu?; Recep Ünal ve Ahmet Taylan, "Sağlık İletişiminde Yalan Haber-Yanlış Enformasyon Sorunu ve Doğrulama Platformları”, Atatürk İletişim Dergisi, 14 (2017).

5 Channel 4 News, "Cambridge Analytica Uncovered: Secret Filming Reveals Election Tricks", erişim 19 Mart 2018, https://www.youtube.com/watch?v=mpbeOCKZFfQ.
} 
(Kenya, bazı Doğu Avrupa ülkeleri, Brexit) benzer şekilde seçimleri yönlendirdiği iddialar arasındadır. Bu örnek siyasal bir manipülasyonun sosyal medya aracılığı ile nasıl gerçekleştirildiğini gösteren iyi bir örnektir. Ne var ki post-truth kavramını gerçekliğin çarpıtıldığı böyle bir örnekle temellendirmek problemli olacaktır.

Kavramı analiz ederken öncelikle Oxford Dictionary’nin verdiği tanımdaki paradoksu ele almak gerekmektedir. Oxford Dictionary tarafindan 2016'da yılın kelimesi seçilen post-truth, kamuoyunun nesnel olgulardan ziyade kişisel duygu ve inançlar tarafından belirlenmesi şeklinde tanımlanmıştır (Oxford Living Dictionaries). Bu tanım yeterince açılkayıcı gözüküyor olsa da esasında daha temel bir kavramsallaştırmaya ihtiyaç duymaktadır. Çünkü duygu ve inançların nesnel hakikatlerin önüne geçmesi meselesi günümüzün bir sorunu değildir. İnsanların, kendileri gibi düşünen ve inanan kişilerin kanaatlerini, hakikatin tam aksi bile olsa, kabul etmeye yatkın olmalarının örnekleri çok fazladır. İnsanın rasyonel davranmak yerine irrasyonel davrandığı, kanaat ve tutumlarının reel olarak belirlenmediği tespitini daha 20. yüzyılın başları sayılabilecek bir tarihte yapan Edward Bernays kitleleri manüple etme konusunda önemli uygulayıcılardan biri olmuştur. Bernays tüketim toplumunun oluşmasına giden bu yola Freud'un fikirlerini uygulayarak başlamıştır. Buna göre id, ego ve süperegodan oluşan insan esas olarak id’de saklanan cinsellik ve saldırganlık başta olmak üzere irrasyonel dürtüler doğrultusunda hareket etmektedir. Başka bir ifade ile Freud, temelde insanın irrasyonel bir varlık olduğunu iddia ediyordu. ${ }^{6}$ İnsanın en rasyonel görünen kararlarının altında bile arzuların yattığını varsayan bu görüş iki alanda uygulamaya dönüşmüştür. Bunlardan biri siyasal diğeri ise ekonomik alandır. Özellikle II. Dünya Savaşı gibi büyük bir yıkıma yol açmış olan bir felaketin temelinde kitlelerin tamamen irrasyonel bir şekilde manipüle edilmesinin etkisi büyüktür. Alman Nazizm’i kitlelerin bilinçaltında saklanan libidinal gücü Hitlere yönlendirirken saldırganlığı ise Ari ırktan olmayan diğerlerine, düşmanlara yönlendirmekteydi. Sonuç olarak ortaya tamamen irrasyonel güçlerin kontrolünde bir siyasal hareket çıkmıştır. İnsanların içinde irrasyonel ve yıkıcı bir gücün var olduğunun somut olarak görülmesi üzerine bu yıkıcı güçlerin tüketime yönlendirilmesini öngören başka bir fikir oluşmuştur. Özellikle Amerika'da görülen ve daha sonra bütün dünyada etkili olan kapitalist tüketim toplumu irrasyonel güçlerin yönlendirildiği ikinci alan olmuştur. Edward Bernays’in başını çektiği kampanyaların temel fikri bir ürünü iyi hissetmek için satın almak üzerinedir. ${ }^{7}$ Neredeyse bütün 20. yüzyılı ve günümüze kadar 21. yüzyllın tüketim anlayışını belirleyen temel ilke insanların kararlarını rasyonel değil irrasyonel zeminde almalarıdır. Kısacası siyaset alanında da tüketim alanında da kamuoyu zaten nesnel olgular tarafından belirlenmemektedir.

Post-truth kavramının, popülist söylemin hakikatin önemini kaybettirdiği ve irrasyonel olanın nesnel olgulardan daha fazla taraftar bulduğu şeklinde tanımlanması sanki daha önce nesnel bir siyaset alanının ve rasyonel kararlar veren

6 Hasan Kaplan, "Psikanaliz Kuramının Yükselen Hermenötik Değeri”, Dini Araştırmalar Dergisi, 11/31 (2008), s.161.

7 Özlem Şendeniz, "Kapitalizm ve Ağız Kokusu: 1920’li Yıllarda Toplumsal Cinsiyet Rollerini Listerine Reklamları Üzerinden İzlemek”, Fe Dergi, 10/2 (2018). 
seçmen kitlesinin var olduğu yanılgısını doğurmaktadır. ${ }^{8}$ Esasında siyaset zaten bir gerçeklik inşa etme sürecidir. Yukarıda da görüldüğü gibi insan davranışı irrasyonel zeminde manipülasyona müsaittir. Hatta meseleye bu açıdan yaklaşıldığında 14 . yüzyılda yaşamış olan İbni Haldun'un şu ifadeleri yalan haberin mahiyeti ve insan davranışının rasyonel zemine oturmayışı bağlamında çok şey ifade etmektedir:

Yalan denen şey haberin yapısına doğal olarak girmiştir. Buna yol açan nedenlerden biri insanların, görüş ve inanış eğilimlerinde yan tutmalarıdır. (...) Eğilimi, bir görüşe bir inanca olan bağlılığ onu kendine bağlamışsa aldığ1 haberler içinde eğilimine ilk anda hangisi uygun düşerse onu kabul eder insan. $\mathrm{Bu}$ eğilim ve yan tutma insanın gerçeği görmeye yarayan gözünde bir perde olur. Eleştirmeyi ve inceleme çabasını engeller. Ve yalanı benimsemeye, alıp aktarmaya sürükler.

Görüldüğü üzere kamuoyunun irrasyonel olan üzerine oluşturulması ve insanların kararlarını irrasyonel olarak alması yeni bir durum değildir. Böyle bir kabul popülist söylemlerini alabildiğine genişleten ve haklı olarak belli kesimleri rahatsız eden Trump'in eleştirisini mümkün kılıyor olsa da aynı zamanda daha önceki ABD başkanlarının oldukça rasyonel davrandıkları, Amerikan halkına ve dünyaya yalan söylemedikleri yanılgısını oluşturarak onların söylemlerini meşrulaştırmaktadır. Örneğin kitle imha silahı bulundurduğu gerekçesiyle Irak’ı işgal eden Bush dönemi Amerikan yönetimi, böyle bir post-truth söylemiyle kendi siyasetini rasyonel ve dürüst olarak gösterme fırsatı bulmakta ve meşruiyet kazanabilmektedir. $\mathrm{Bu}$ anlamıla hakikat sonrası siyaset (post-truth politics) kavramının içi boş ve temelleri gevşek bir kavram olduğunu iddia etmek yanlış olmayacaktır.

Sonuç olarak şu hususları tespit etmek gerekmektedir:

1) Post-truth kavramı irrasyonel kanaat ve hislerin kamuoyunu belirlemede nesnel olgulardan daha etkin olduğu şeklinde tanımlanıyorsa kavramı Trump’n başkan seçilmesi ve Brexit sürecindeki popülist söylemlerden bağımsız olarak ele almak gerekir.

2) Post-truth kavramı basitçe, gerçekliğin çarpıtılması, popülist söylemlerin artması, yalan haberlerle kamuoyunun yönlendirilmesi olarak ele alınamaz.

3) Post-truth kavramı sosyal medya ile ilişkilendirilerek ele alınacaksa sosyal medyanın hakikat kavramına nasıl bir etkide bulunduğu tartışılmalıdır. Böyle bir tartışma ise medyanın insan tipolojisine etkisi çerçevesinde medyanın yapısı, medya epistemolojisi ve hakikat-medya ilişkisi etrafında gerçekleştirilmelidir.

\section{Teknolojik Determinizm ve Medya Epistemolojisi}

Genel olarak teknoloji özelde ise iletişim teknolojileri toplumların örgütlenme biçimlerini, kültürlerini ve insan tipolojilerini belirleme noktasında etkilidirler. Tarihsel süreç içerisinde farklılaşan iletişim teknolojileri farklı kültürler ve zihinsel

8 Aybars Yanık, "Popülizm (V): Post-truth”, Birikim Dergisi, 11 Ağustos 2017, http://www.birikimdergisi.com/ haftalik/8463/populizm-v-post-truth\#.XIBWv-gzZPY.

9 İbni Haldun, Mukaddime cilt I, Ankara: Onur Yayınları, 1977, s.123-124. 
süreçler meydana getirmiştir. Bu çalışmada ele alınan post-truth kavramı da tarihsel sürecin son kertesinde ortaya çıkan elektronik medya ve daha belirgin olarak sosyal medyanın yeni bir insan tipolojisi oluşturduğu iddiası üzerinden ele alınacaktır. Zira hakikat kavramı kullanılan iletişim aracının (medya) yapısından bağımsız olarak ele alınamaz. Bu bağlamda post-truth kavramını yalnızca gerçekliğin çarpıtılması olarak ele almak yerine elektronik medya epistemolojisinin meydana getirdiği bir zihinsel durum olarak ele almak gerektiği düşünülmektedir.

Teknolojik determinizm kabaca teknolojinin toplumu belirlemesi şeklinde tanımlanır. Daha detaylı bir tanım yapmak gerekirse teknolojik determinizm, ortaya çıkan yeni teknolojilerin ekonomi, siyaset, kültür gibi toplumun temel bileşenlerini değiştirmesi, dönüştürmesi ve belirlemesidir denilebilir. Yapıp etme "tekhne" ve bilgi "loji” kelimelerinin birleşmesiyle oluşan ve yapıp etmenin bilgisi anlamına gelen teknoloji, her ne kadar toplumun uğraşları ve planlı çabaları sonunda ortaya çıkan bir bilgi türü olsa da nihayetinde toplumu belirleme gücüne sahip olduğunu da belirtmek gerekir. Teknolojinin toplumların ekonomik, siyasal, kültürel yapılarını hatta daha temelde insan tipolojilerini nasıl belirlediğini tarihin başlangıcından itibaren gözlemlemek mümkündür. Özellikle medya teknolojilerindeki gelişmelere bakıldığında bu durum açıkça gözlenmektedir. Walter Ong, Harold İnnis, Marshall Mcluhan, Neil Postman gibi düşünürlerin medya teknolojilerindeki değişimler hakkındaki teorilerine bakıldığında, medya teknolojilerinin toplumu ve insan tipolojisini temelden belirlediği şeklindeki abartılı görünen önerme, çok daha kabul edilebilir hale gelmektedir.

İletişim alanındaki çalışmalarda Mcluhan ile özdeşleştirilen teknolojik determinizm daha çok teknolojiyi olumlama bağlamında ele alınmaktadır. ${ }^{10}$ Teknolojinin kültürü ve insan tipolojisini belirlediği tezinden hareket ederek elektronik medya çağında insanlığın çok daha iyi bir dünyada yaşayacağını iddia eden Mcluhan’ın bu olumlaması teknolojik determinist görüşün de teknolojiyi daima olumladığ 1 yanılgısını yaratmaktadır. Bu çalışmada teknolojik determinizm, bir dönemin başat medyasının yapısından kaynaklı olarak o dönemin kültürünü ve insan tipolojisini belirlediği fakat bu durumun olumlu veya olumsuz yönleri olabileceği şeklinde ele alınacaktır.

Ong’un sözlü kültür ile yazılı kültürü derinlemesine inceleyerek karşılaştırdığı ünlü eserinde ${ }^{11}$ alfabenin toplumu ve insanı, bir başka deyişle kolektif düşünceyi ve bireysel düşünceyi nasıl dönüştürdüğü detaylıca ele alınmaktadır. Ong’a göre yazı öncesi insanı kendi bilincine ve düşüncesine odaklanabilen bir zihin yapısına sahip değildir. Zira yazı öncesi kültür, bilginin "söz"de saklandığı bir çağdır. Bilgi atasözlerinde, mitlerde ve kuşaktan kuşağa aktarılan anlatılarda var olabilen bir mahiyete sahiptir. ${ }^{12}$ Alfabe teknolojisiyle birlikte bilgi, zihin dışında başka alanlarda saklanabilme imkanı bulmasının yanı sıra listeleme, sıralama, soyutlama, sınıflandırma ve açıklama gibi düşüncenin farklı boyutları da ortaya çıkabilmiş ve

10 Erkan Yüksel, İletişim Kuramları, Eskişehir: Anadolu Üniversitesi Yayınları, 2013, s.107.

11 Walter Ong, Sözlü ve Yazılı Kültür, İstanbul: Metis Yayınları, 2013.

12 Ong, Sözlü ve Yazılı Kültür, s.37. 
analitik düşünce mümkün hale gelmiştir. ${ }^{13}$ Felsefenin ve bilimsel düşüncenin ortaya çıkabilmesi kaçınılmaz olarak alfabe teknolojisinin bulunmasına bağlıdır. Bunun yanı sıra yazı, bilginin nesnelleşmesini ve bilen ile bilinen arasına mesafe koymayı da sağlamıştır. ${ }^{14} \mathrm{Bu}$ da insana kendi zihnini ve benliğini dışarıdan gözlemleme imkanı kazandıran bir teknolojiye sahip olması anlamına gelir. Alfabe teknolojisinin zihnin işleyişi ve insan tipolojisinde meydana getirdiği değişim üzerinde duran Ong'un yanı sıra bu teknolojinin toplumsal yapılarda meydana getirdiği değişim de çokça ele alınmıştır. Bilginin, zihin dışında bir alanda depolanabilmesi imkanını veren alfabe teknolojisi ticari faaliyetlerin ve sosyal örgütlenmelerin daha kolay yapılabilmesini sağlamıştır. Bu sayede daha büyük şehirler ve daha karmaşık yapılara sahip yönetimler ortaya çıkabilmiştir. İnnis ise alfabenin kendisinden ziyade yazının üzerine yazıldığ 1 malzeme üzerinden determinist bir görüş bildirir. Buna göre yazının papirüs ve kağıt üzerine yazılarak kolayca taşınması krallıkların genişlemesine ve merkezi imparatorlukların ortaya çıkmasına zemin hazırlamıştır. Kolay taşınabilme özelliğine sahip bu medyayı mekana dayalı medya olarak isimlendiren İnnis ${ }^{15} \mathrm{kil}$, taş ve parşömen gibi malzemelerin kullanıldığı medyayı zamana dayalı medya olarak tanımlar. Mekana dayalı medya kolay taşınabilir olduğu için merkezi yönetimin "söz"ünü uzaktaki hakimiyet alanlarına da taşıyabildiğinden dolayı kağıt ve papirüs kullanımının yaygınlaşmasıyla birlikte Mısır, Pers ve Roma gibi imparatorluklar ortaya çıkmıştır. ${ }^{16}$ Dolayısıyla sözlü kültürün insanı ile yazılı kültürün insanının tipolojisi arasında fark olduğu gibi toplumsal, ekonomik ve siyasal yapılar arasında da fark vardir.

Alfabe teknolojisinin meydana getirdiği değişimden belki de daha fazlasını basılı medyanın yani matbaanın getirdiğini çarpıcı şekilde ortaya koyan Mcluhan ünlü eseri Gutenberg Galaksisi'nde ${ }^{17}$ fonetik alfabenin ve basılı medyanın, farkına kolayca varılamayan etkilerini irdelemektedir. Tıpkı kolay taşınan papirüsün merkezi imparatorlukları ortaya çıkarması gibi basılı medyanın da ulusçuluğu ortaya çıkardığını ve bireyselleşen insan tipolojisinin matbaa ile mümkün olduğunu belirtir. Basılı medyanın çizgisel (lineer) yapısı mekanik bir dünya algısı oluşturmuştur. ${ }^{18}$ $\mathrm{Bu}$ da yaşamın kutsaldan arınmasını yani sekülerizmi doğurur. ${ }^{19}$ Basılı medyanın yapısından kaynaklanan bir diğer durum kitabın yalnız okunması ve sesi insanın içine hapsetmesidir. Bu özellik insanın kendini gözlemlemesi fırsatını verdiği gibi bireyin ortaya çıkışını, yalnızlaşmayı ve toplumdaki sıcak cemaat bağlarının parçalanmasını da beraberinde getirmiştir. Yine aynı şekilde basılı medya anadilde yazmayı ve okumayı teşvik eden netice olarak ulusçuluğu ortaya çıkaran ana etkendir. ${ }^{20}$ Mcluhan içerikte ne olduğundan bağımsız olarak bir aracın (medya) bizatihi kendisinin yeni bir insan tipolojisi meydana getirdiğini iddia eder. Ona göre sözün egemen

13 Ong, Sözlü ve Yazll Kültür, s.21.

14 Ong, Sözlü ve Yazılı Kültür, s.62.

15 Harold İnnis, İmparatorluk ve İletişim Araçları, Ankara: Ütopya Yayınları, 2007, s.28.

16 İnnis, İmparatorluk ve İletişim Araçlar, s.31.

17 Marshall Mcluhan, Gutenberg Galaksisi, İstanbul: Cogito, 2017.

18 Mcluhan, Gutenberg Galaksisi, s.321-325.

19 Mcluhan, Gutenberg Galaksisi, s.111-113.

20 Mcluhan, Gutenberg Galaksisi, s.279-280. 
olduğu dünya sıcak ilişkilerin, cemaatin güçlü bağlarının hakim olduğu bir "kulak" dünyasıdır. "Göz"ün dünyası olan basılı medya çağı bireyselleşmeyi, ulusçuluğu ve sekülerizmi tetikleyerek kulağın dünyasını parçalayan bir çağ olarak olumsuzlanır. ${ }^{21}$ Mcluhan her dönemin başat medyasının toplumun yapısını belirlediğini ortaya koymuştur. Onun meşhur "araç mesajdır" (the medium is the message) sözü tam olarak bu belirlenime işaret etmektedir.

Teknolojinin insanı belirlediği düşünesine katılan bir başka düşünür Neil Postman'dır. Temelde Mcluhan ile aynı noktada buluşsa da basılı ve elektronik medya teknolojilerinin insanda ve kültürde meydana getirdiği değişikliklerin iyi veya kötü olması noktasında tam tersi bir düşünceye sahiptir. Mcluhan’ı "araç mesajdır" ifadesine karşılık "araç metafordur" ifadesini kullanır. Ona araç mesajdır sözü kültürün her iletişim aracılığıyla yeni baştan yaratılmasıdır ve somut bir açıklamayı yansitır. Aracın metafor olması ise dünyanın insanlar adına sınıflandırılması, sıraya sokulması belli bir çerçeve çizilmesi, genişletilip küçültülmesi, hakikatin tanımlanması ve dünyanın görünümüne ilişkin tezlerin ortaya atılması anlamına gelir. ${ }^{22}$ Herhangi bir aracın dolayımı olmadan insanın hiçbir şeyi göremeyeceğini ve bilemeyeceğini şöyle ifade eder: ${ }^{23}$

Yeni bir medium yalnızca insanın zihinsel kapasitesinde ve bilme kapasitelerinde değişikliğe yol açmaz aynı zamanda yeni bir medium söylem yapısını da değiştirir. Söylem yapısını aklın kullanılışının bazı yollarını cesaretlendirerek belli zeka ve bilgelik tanımlarını öne çıkarır ve belli türde içerik talep eder. Televizyonun yarattığı epistemolojinin basılı söze dayalı epistemolojinin gerisinde kaldığına inanmakla yetinmiyor ayrıca bunun tehlikeli ve anlamsızlı̆ğ egemen kılan bir gelişme olduğuna da inanıyorum.

Postman medya metafordur sözünün yanı sıra belli bir medyanın yapısından kaynaklanan belirleme gücünü ifade etmek için "medya epistemolojisi" ifadesini kullanır. "Dil bizim medyamızdır, iletişim araçlarımızdır. Medyamız metaforlarımızdır. Kültürümüzün içeriğini metaforlar yaratır"24 derken veya "matbaa bir metafor işlevi, ciddi ve rasyonel bir kamusal konuşma biçimi yaratacak bir epistemoloji işlevi görür"25 cümlesini kurarken medyanın metafor olmasının belli bir epistemolojiye sahip olması anlamına geldiğini, içerikten bağımsız olarak belli bir gerçeklik sunduğunu söylemektedir. Postman medyanın bir inceleme nesnesi olarak ele alınırken epistemoloji üzerinde durmanın gerekli olduğunu zira hakikat tanımlarının doğduğu kaynağın epistemoloji olduğunu ve hakikat tanımlarının enformasyonu taşıyan medyanın karakterine bağlı olduğunu ifade eder. ${ }^{26}$

Ong, İnnis ve Mcluhan gibi Postman da "medya epistemolojisi” olarak isimlendirdiği

21 Fahrettin Altun, "M. McLuhan ve J. Baudrillard’ın Medya Kuramlarının Karşılaştırmalı Çözümlemesi”, Yayınlanmamış Doktora Tezi, İstanbul Üniversitesi SBE, 2006, s.215-217.

22 Neil Postman, Televizyon: Öldüren Eğlence, İstanbul: Ayrıntı yayınları, 2012, s.19.

23 Postman, Televizyon: Öldüren Eğlence, s.37.

24 Postman, Televizyon: Öldüren Eğlence, s.24.

25 Postman, Televizyon: Öldüren Eğlence, s.55.

26 Postman, Televizyon: Öldüren Eğlence, s.26. 
kavramla bir çağın başat medyasının toplumu ve kültürü belirlemesini işaret eder. Fakat bunlardan da bir adım öteye giderek hakikat tanımlarının da medyanın epistemoljisine bağlı olarak ortaya çıktığı iddiasında bulunur. Matbaa çağını olumlayan bir düşünür olarak Postman telgraf ve fotoğrafın icadıyla başlayıp televizyon ile devam eden elektronik kültürü adeta lanetler. Ona göre basılı medyanın epistemolojisi analitik düşünceyi, derin tahlilleri, karşılaştırmalı fikirleri önceleyen bir yapıya sahiptir. Telgraf ve fotoğraf ise yapısı gereği bağlamdan kopuk ve düşünceye izin vermeyen bir medya epistemolojisine sahiptir.

Bahis mevzuu edilen düşünürlerin fikirleri normatif anlamda bir birlerin ayrılsa da vardıkları olgusal yargılar bir noktada birleşmektedir. Bu çalışmanın da dayanak noktasını oluşturan bu önerme her medya teknolojisinin yapısı gereği bir epistemoloji dayattı̆̆1 ve her çağın başat medyasının epistemolojisi çerçevesinde o çağın toplum yapısının belirlendiğidir. Günümüzde tartışılan "post-truth” kavramının postmodern çağ ile bağlantılı olduğu, bunun ise dijital medya teknolojilerinin epistemolojisine bağlı olarak ortaya çıktığ 1 iddia edilmektedir.

\section{Postmodernizmin Hakikat Algısı ve Sosyal Ağların Epistemolojisi}

Metin kelimesi bir yazınsal bütünlügü ifade etmesinin yanı sıra sağlamlık anlamına da gelir. İki farklı kavramın metin kelimesiyle ifade edilmesi basit bir eş anlamlılığın ötesindedir. Zira yazı ile kayıt altına alınarak saklanmış olan bilgi sabitlenmiş ve sağlam bir zemine oturtulmuş olan bilgidir. Medya epistemolojisi açısından bakıldığında kitabın ve dolayısıyla metnin sahip olduğu bu dirençli yapı modernizmin "tek hakikatç" (monik) tarafını beslemiştir. Matbaanın icadı sonrasında Avrupa merkezli olmak üzere ortaya çıkan aydınlanmacı hareket ağırlıklı olarak basılı medyanın epistemolojisinin gereği olarak yükselmiştir. Modern felsefenin öncüsü kabul edilen Descaretes'in cogitosu (düşünüyorum, o halde varım) bile basılı medyanın yani kitabın, düşünceyi derinleştirme, zihnin kendi kendisi üzerine düşünebilme ve var olmayı bile düşünceye dayandırma gücünün bir sonucudur. ${ }^{27}$ Modern çağın sahip olduğu tek ve mutlak hakikat düşüncesi metnin sızdırmaz, sabit ve güçlü epistemolojisinin bir sonucudur demek çok da abartılı bir iddia olmayacaktır.

Evrensel bir hakikatin varlığı tartışması ilkçağ felsefesine, sofistlerle Sokrates’in tartışmalarına kadar götürülebilir. Sofistler tek bir hakikatin olmadığını, her şeyin ölçüsü olan insana göre şekillenen çoklu hakikatlerin olduğunu iddia ederlerken Sokrates insanın varoluşunun ötesinde herkesi bağlayan bir evrensel hakikat fikrinin olduğunu savunmuştur. ${ }^{28}$ Tam da mitostan logosa, sözden yazıya geçişin gözlendiği bu dönüşüm, eksen çağ ${ }^{29}$ olarak ifade edilen ve doğal toplum modelinin yerini yavaş yavaş sembolik toplum modeline ${ }^{30}$ biraktığ ${ }_{1}$ bir dönemi işaret etmektedir. Gerek Sokrates sonrası Platoncu felsefe gerekse tek tanrılı dinlerin algısında mutlak bir hakikatin varlı̆̆ı sorgulanmaya kapalıdır. Postmodernizm dönem hakikatin

27 Klaus Bruhn Jensen, “Nitel Bilim Olarak Beşeri Araştırmalar: Kitle İletişi̇m Araçlarına Katkılar”, Medya ve İzleyici, der., Şahinde Yavuz, Ankara: Vadi Yayınları, 2005, s.30.

28 Ahmet Cevizci, Felsefeye Giriş, İstanbul: Say Yayınları, 2012, s.222.

29 Robert Neelly Bellah, "What is Axial About the Axial Age?", European Journal of Sociology, 46/1 (2005).

30 İlkay Sunar, Düşün ve Toplum, Ankara: Kültür Bakanlığı Yayınları, 1979, s.51-53. 
izafiliğini vurgulamaktadır. ${ }^{31}$ Hakikatin tek olduğu fakat farklı görünümleri olabileceği ve hakikate hangi yollarla ulaşılabileceği tartışmaları daima var olduğu halde postmodern dönemde hakikatin izafi olduğu dolayssılla evrensel bir hakikatin olmadığı̆ düşüncesi sofistlerin henüz mitosun dünyasından kurtulamamış fikirlerine adeta bir geri dönüşü hatırlatmaktadır.

Modernizm ilerlemeci tarih anlayışına dayanan, gelişmeci, bilimci, rasyonel tavra sahip $^{32}$ ve dolayısıyla tek bir doğru fikrine sabitlenmiş bir düşüncenin ürünüdür. Bu monik düşünce "epistemik mutlakiyetçilik" ve "radikal rölativizm" olmak üzere iki uç anlayış doğurmuştur. ${ }^{33}$ Epistemik mutlakiyetçilik bilginin varlı̆̆ın göreceli olabileceğini toptan reddederek hakikate ulaşmanın tek bir yolu olduğunu iddia etmiştir. Radikal rölativizm ise hakikatin varlığını toptan reddeder. Bu, bütün doğruların ve erdemlerin bireyin konumuna göre şekillendiği ve bireyin durduğu merkeze atıfla herkesin farklı hakikat algısının olduğu dolayısıyla hakikatin izafi hale geldiği postmodern bir algının ifadesidir. Böyle bir algı ontolojik bir kaos içerisinde kalmış zihni ve siyasal, sosyal, ekonomik ve kültürel alanlarda makro anlatıların yerine geçen mikro anlatıları doğurmuştur.

Postmodernizmin öncü düşünürlerinden kabul edilen François Lyotard'ın modernizmin metinlerini kötülediği ve postmodern çağın çoklu hakikat dünyasını göklere çıkardığı eserlerinde, çağın değişen başat medyasının insan tipolojisine etkisi fark edilir. Lyotard modernizmin kesinlik ve mutlak hakikat iddialarını sert şekilde eleştirirken postmodern çağı olumlar. Çünkü Lyotard’a göre postmodern çağda görselliğin ve imgenin yeniden doğuşu metnin sıkıcı ve hegemonik yapısını yıkacaktır. ${ }^{34}$ Fotoğraf ile başlayan görsel çağ sinema ve televizyonla birlikte coşkulu ve şenlikli bir sirke dönüşecektir. Bu yeniçağda metnin ağır söylemlerinin, büyük anlatıların, tek hakikat iddiasındaki modern düşüncenin yerini hisler, tecrübe, coşku, küçük anlatılar ve aynı anda mümkün olabilen farklı hakikatler alacaktır ${ }^{35}$ Postmodern dönemin başat medyası olan elektronik medyanın epistemolojisi "küçüğün güzelliği”ne övgüler düzen, büyük anlatıları alaya alıp küçük düşüren bir gerilla anlatısının kurulmasına zemin teşkil eder.

Postmodern dönemde hakikat fikri görüntünün arkasında kalmış, sınırsız sayıdaki kopya ve dış görünüş özün ve gerçeğin yerini almıștır. Hakikat yalnızca bir yanılsama ve eğlenceden ibaret olmaya başlamıştır. ${ }^{36}$ Baudrillard'a göre ise hakikat fikrinin önünde, gerçekliğin yok edilmiş olması gibi bir engel durmaktadır. Onun meşhur kavramı olan simülasyon, gerçeğe ait tüm göstergelerin ele geçirildiği gerçeğin yerine geçmiş sahte gerçeklik olarak tanımlanabilir. Sinsice gerçeği yok edip yerine geçmiş olan hipergerçektir. Taklit, bir simülasyon değildir. ${ }^{37}$ Çünkü taklit, aslıyla

31 İbrahim Kalın, Akıl ve Erdem, İstanbul: Küre Yayınları, 2013, s.257.

32 Süleyman Hayri Bolay, "Postmodernizm”, Moderniteden Postmoderniteye Değişim, der., Coşkun Can Aktan,

Konya: Çizgi Kitabevi, 2003, s.67.

33 Kalın, Akıl ve Erdem, s.247.

34 Jean-François Lyotard, Postmodern Durum, Ankara: Vadi Yayınları, 1994.

35 Michael Ryan ve Douglas Kellner, Politik Kamera, İstanbul: Ayrıntı Yayınları, 2011, s.182-201.

36 Guy Debord, Gösteri Toplumu, İstanbul: Ayrıntı Yayınları, 2012, s.34.

37 Jean Baudrillard, Simülasyon ve Simulakrlar, Ankara: Doğu Batı Yayınları, 2011, s.16. 
kıyaslanarak ayırt edilebilir. Oysa simülasyonda artık sahte ve hakiki gibi iki ayrı şey yoktur. Gerçeğin tüm göstergelerine sahip olan simülasyon gerçekliği yok edince artık o gerçekliği imgelemenin imkanı da ortadan kalkar.

Boş zamanın üretilmesi ve yönetilmesiyle ortaya çıan ticari alanda bireyin tüm etkinlikleri kontrol altındadır. Bu kontrol eğlence, sinema, müzik gibi kültürel unsurların endüstri haline getirilmesi ile sağlanır. Gösteri sanatlarından oyunlara, spor faaliyetlerinden turizme kadar pek çok alan bu endüstrinin denetimindedir. Buna bağlı olarak sinema salonları, alış veriş merkezleri, lunaparklar, yüzme havuzları, fitness salonları, stadyumlar gibi yeni tüketim mekanları ortaya çıkar. Bütün bu boş zaman faaliyetleri Baudrillard’n ifadesiyle birer simülasyona dönüşür. Baudrillard'ın, simülasyona örnek olarak verdiği şeylerden biri de Disneyland'dir. Disneyland aslında Amerikảnın gerçek olduğunu onaylatmaya çalışan bir simülasyondur. Yapılmak istenen Disneyland'in Amerika’nın bir taklidi olduğuna inandırılarak Amerika’nın gerçekliğini onaylatmaktır. Oysa Amerika’nın kendisi de ne gerçektir ne de bir gerçekliğin taklididir. Baudrillard "Amerika" isimli kitabında Amerika’nın bir hipergerçeklik olduğunu anlatır (Baudrillard, 2006). ${ }^{38} \mathrm{Bu}$ durumda Disneyland Amerika gerçekliğini yeniden üretmek üzere tasarlanmış bir simülasyon evrenidir. ${ }^{39}$

Baudrillard'n en bilinen örneklerinden biri olan Körfez Savaşı ona göre medyanın vasıtasıyla oluşturulan bir simülasyondur. Esasındahiçbirşekildebir savaşyaşanmamış olduğu halde medyada ve özellikle televizyonlarda yayınlanan görüntüler bir savaş simülasyonunu meydana getirmiştir. Savaşın(!) sembol görüntülerinden biri olan petrole bulanmış kuş görüntüsünün esasında Fransa açılarında kaydedildiğinin sonradan ortaya çıkması simülasyonun nasıl bir hipergerçeklik olarak mümkün olabildiğini göstermektedir. Baudrillard’a göre özellikle Batı toplumlarında zihinlerin hakikat ile bir ilişkisi kalmamış ve bütün gerçekliğin tasfiye edildiği bir simülasyon çağının kapısı aralanmıştır. ${ }^{40}$ Artık hakikati bulmak mümkün değildir çünkü bu yeniçağda medyanın ürettiği şey yalan veya taklidin ötesinde gerçekliğin öldürülmesi ve onun yerine gerçekliğin bütün izlerini taşıyan başka gerçekliklerin alması durumudur. Bu hipergerçeklik hiçbir gerçek gerçekliğe dayanmaksızın kendini sınırsız sayıda üretme yeteneğine de sahiptir.

Medya, kamuoyunun hakikate ilişkin fikirlerini tanımlama ve düzenleme biçimini belirler. ${ }^{41}$ Bir diğer ifade ile hakikati tanımlamanın farklı biçimleri vardır ve bu biçimler kullanılan aracın (medya) yapısına göre değişmektedir. Elektronik medya çağının başlangıcı kabul edilen telgrafın bir medya olarak nasıl bir epistemolojiye sahip olduğunu ve bilgiyi nasıl dönüştürdüğünü Postman şöyle ifade eder: ${ }^{42}$

Telgraf ilgisizlik, etkisizlik ve tutarsızlığı geniş ölçüde yayarak tipografinin söylem alanına üç koldan saldırmıştı. Telgrafın bağlamsız enformasyon fikrine

38 Jean Baudrillard, Amerika, İstanbul: Ayrıntı Yayınları, 2006.

39 Baudrillard, Simülasyon ve Simulakrlar, s.30.

40 Baudrillard, Simülasyon ve Simulakrlar, s.15.

41 Postman, Televizyon: Öldüren Eğlence, s.27.

42 Postman, Televizyon: Öldüren Eğlence, s.79. 
bir tür meşruiyet kazandırması bu söylem iblislerini canlandıran bir etkendi. Bağlamsız enformasyon fikir enformasyonun değerinin onun toplumsal ve politik kararlarla eylemlerde ve görebileceği işleve bağlı olmasının gerekmediği, ama değerinin onun yeniliği, ilginçliği ve özgüllüğüne bağlanabileceği düşüncesini içeriyordu. Telgraf, enformasyonu bir meta yararı veya anlamına bakılmaksızın alınıp satılabilecek bir "şey" haline getirmekteydi.

Telgraf ve fotoğrafla birlikte enformasyon, bağlamından koparılmış bir duruma düşmüştür. Fotoğraf, yani görüntüye dayalı medyanın yükselişi ise dünyanın bir fikir olarak algılanmasından nesne olarak algılanmasına geçişi göstermektedir: ${ }^{43}$

Fotoğraf genel olarak insandan değil bir insandan, genel olarak ağaçtan değil bir ağaçtan bahseder. Nasıl denizin fotoğrafını çekemezseniz doğanın da fotoğrafını çekemezsiniz. Yalnızca şimdi ve burada gördüğgunüz belli bir kesiti fotoğraflayabilirsiniz. Ve nasıl doğayı ve denizi fotoğraflayamazsanız hakikat, onur, aşk, yalan gibi daha geniş soyutlamalar hakkında görüntü sözlüğüyle konuşamazsınız. Çünkü bir şeyi göstermek ile bir şey hakkında konuşmak bambaşka iki süreci anlatır. Resimlerin tanınması sözcüklerin ise anlaşılması gerekir. Fotoğraf dünyayı nesne olarak dil ise fikir olarak sunar.

Postman televizyonun epistemolojisi hakkında da şunları söyler: ${ }^{44}$

Televizyon üst araç (meta-medium) statüsüne yalnızca dünyaya ilişkin bilgimizi değil aynı zamanda bilme yollarına ilişkin bilgimizi de yönlendiren bir araç statüsüne yükselmiştir. (...) Televizyonun hakikat, bilgi ve gerçeklik tanımlarını o kadar gözü kapalı kabul etmekteyiz ki ilgisizlik bize anlamlı görünmekte, tutarsızlık ise özellikle akıllıca davranmak gibi gelmektedir.

Postmodern döneme medya açısından yaklaşıldığında telgraf, fotoğraf, televizyon ve sonrasında sosyal medyanın sahip olduğu epistemolojinin dünyayı algılama ve tanımlama biçimlerini ilgisizlik ve eğlence temeline doğru sürüklediğini görmek mümkündür. Post-truth kavramının anlamı da tam olarak bu anlamsızlı̆ıı hüküm sürdüğü yeni medyanın epistemolojisinde saklıdır.

Post-truth kavramı literatüre kazandıran Ralph Keyes'in "Hakikat Sonrası Çağ" isimli kitabında ${ }^{45}$ ortaya koyduğu değerlendirme de esasında teknolojik determinist bir bakışa sahiptir. Kavramı basitçe yalan söylemek ve yalan ile yönlendirmekten öte postmodernizmin radikal rölativist anlayışıyla teknolojik araçlar ve medya arasındaki bağ irdeleyerek temellendirmeye çalışan Keyes, televizyon ve internet üzerinden pek çok örnek vermektedir. Keyes’e göre televizyon, yapısı gereği dramatik unsurları olgusal unsurlara tercih etmektedir. Bu sebeple kurmaca olmayan programlar bile kurmaca programların yöntemlerini kullanır. ${ }^{46}$ Zira televizyon görselliğe dayanan bir medya olarak gösteri aracına dönüşmek zorundadır. Yapısı gereği televizyon

43 Postman, Televizyon: Öldüren Eğlence, s.86.

44 Postman, Televizyon: Öldüren Eğlence, s.92-93.

45 Ralph Keyes, Hakikat Sonrası Çă̆, İzmir: Deli Dolu Yayınları, 2017.

46 Keyes, Hakikat Sonrası Çă̆, s.230. 
görüntüyü öze tercih eder. Sadece aldatmacaya yatkın olmayan bunu açıça teşvik de eden televizyon ${ }^{47}$ kurmacanın kaçınılmazlığıyla sürekli popülizm üretir. Neil Postmann’ın siyasal aktörler üzerinden verdiği çarpıcı örnek değişen medyanın insan tipolojisini nasıl belirlediğini göstermek açısından önemlidir. ${ }^{48}$ Abraham Lincoln ile rakibi Stephen Douglas'ın girdikleri siyasal tartışmalarda izleyicilerin konuşmacıları nasıl saatlerce dinleyebildikleri ve konuşmacıların kurdukları uzun cümleleri nasıl takip edebildiklerini anlatan Postman bu tipolojinin basılı medya epistemolojisinin bir sonucu olduğu ifade etmektedir. Fakat görüntü teknolojilerinin artmasıyla birlikte siyasal aktörlerin olgular üzerinden kurdukları argümanlar ile ikna etme yöntemleri; yerini, aktörlerin görüntü yani imaj üzerinden ikna yöntemlerine bırakmıştır. Bir başka ifade ile siyasal fikirler ve yetenek yerine siyasal aktörün yetenekli olduğu veya siyasal fikirlerinin daha geçerli olduğu algısını uyandıracak görünümler sergileme eğilimi geçmiştir. Keyes’e göre televizyondaki imgeler dürüstlükle değil dürüstlügün görünümüyle ilgilidir. Görüntü odaklı bir medya olarak yapısı gereği dramatik yoğunluğu önceleyen televizyon her zaman duyguları gerçeklere tercih etmektedir. ${ }^{49}$ Yapısında gösterinin, kurmacanın ve popülizmin yer aldığı televizyon haberlerden eğlence programlarına, dizilerden reklamlara kadar ürettiği tüm içeriklerle zaten post-truth çağının başat medyasıdır.

Keyes'e göre post-truth'a zemin hazırlayan şey işte bu modern teknolojidir. ${ }^{50} 2004$ gibi, sosyal medya hakkında söz söylemenin henüz oldukça erken olduğu bir yılda kaleme aldığı kitabında genel olarak internet teknolojilerinin yapısı hakkında önemli değerlendirmeler yapan Keyes'in tespitleri, günümüzde kitle iletişiminin odağına yerleşen sosyal medya için de geçerlidir. Televizyonda kurmacayı pasif şekilde alan izleyici internetle birlikte katılımcı da olmuştur. Yukarıda da değinildiği gibi bu katılımcılık görünürde özgürlükçü bir alana işaret etse de Keyese göre sahtekarlığa karşı çok az yaptırımın olduğu siber uzay etikten muaftır. Hakikat fikrinin tamamen yok olduğu internet dünyası post-truth tohumlarının yeşermesi için mükemmel bir seradır. ${ }^{51}$ Televizyon kurmacayı merkeze aldığ 1 gibi internet teknolojileri de anonimliği merkeze alır. Anonim olabilmek ihtiyatlı olma zorunluluğunu ortadan kaldırdığı gibi ${ }^{52}$ kullanıcıların, sorumluluk fikrinin gereksizliğine de inanmalarını sağlar. Siber uzayın şenlikli dünyasında sorumluluk fikrinden kurtulan insanın hakikatin ne olduğuna dair sorgulamada bulunması beklenemez. Günümüzde sosyal medya ve etik bağlamında tartışılan yalan haber, manipülasyon, yankı fanusları gibi meselelerin temelinde internet medyasının yapısı vardır. Zira hem yalan haber hem manipülasyon hem de sürekli kendi fikirlerini destekleyici paylaşımlarla karşılaşmak anlamına gelen yankı fanusları internet teknolojileri ile birlikte ortaya çıkmamış olsalar da özellikle sosyal medya ile birlikte ciddi bir değişim geçirmişlerdir. Bu değişim hakikatin çarpıtılmasından öte hakikat arayışının anlamsızlaşması, bir anlamda hakikatin yitimidir. Keyes'e göre siber uzay derinlik yerine yüzeydeki

47 Keyes, Hakikat Sonrası Çă̆, s.231.

48 Postman, Televizyon: Öldüren Eğlence, s.56-60.

49 Keyes, Hakikat Sonrası Çă̆, s.233.

50 Keyes, Hakikat Sonrası Çă̆, s.255.

51 Keyes, Hakikat Sonrası Çă̆, s.259.

52 Keyes, Hakikat Sonrası Çă̆, s.264. 
postmodern değerlere, gerçeklik yerine simülasyona ve ciddiyet yerine oyunbazlığa biçim verir. ${ }^{53}$ Satır aralarında teknolojik determinist bakış açısı oldukça rahat gözlemlenebilen Keyes bu yeni teknoloji hakkında şöyle söyler: ${ }^{54}$

İnternet ağı, gerçek gibi sunulan dedikoduların, haber olarak verilen basın bültenlerinin, aldatmacalı reklamların, kötü niyetli söylentilerin ve katıksız dümenlerin bir karışımıdır. İnternet bilerek merkezsizleştirilmiş bir araç olarak tasarlandığ 1 için hangisinin hangisi olduğunu denetleyecek yeterli denetleyici olmaksızın doğru ve yanlış bilgiyi ayrım yapmadan birleştirir. (...) Sonuç olarak internette doğruluk, tamamen göreceli bir kavramdır. (...) İnternet için hiçbir söylenti fazla rezil, hiçbir paranoyak hezeyan aşırı değildir.

Merkezsiz ve kontrolsüz bir yapıya sahip olan internet medyası doğruluğu göreceli hale getirmesinin yanı sıra doğruluğu anlamsız hale de getirmektedir. Anlamsızlaşma bir hakikat yitimidir. Post-truth kavramını Keyes'in ifade ettiği bu noktalar dışında anlamsızlaşma ve anlam veya doğruluk arayışının gereksiz hale geldiği bir çağ olarak okumak gerekir.

Toplumların eski devirlerden bu yana yalan haberler ile yönlendirilip kontrol edilmesi bilinen bir durumdur. İçinde yaşadığımız postmodern çağın durumunun farklı olması hakikat arayışının ortadan kalkması ile ilgilidir. Bir başka ifade ile premodern dönem hatta modern dönem teknik olarak yalana müsaade etse de epistemolojik olarak hakikatin varlığını inkar etmemesine karşı postmodern dönem teknik olarak yalana daha fazla müsaade etmesinin yanı sıra epistemolojik olarak zaten bir hakikat fikrini reddeder haldedir.

Sosyal medya ve artık sosyal medya ile entegre hale gelmiş olan konvansiyonel medyanın yapısında hız, yüzeysellik, katılımcılık, merkezsizlik ve niceliğin büyüklüğü gibi özellikler mevcuttur. Sosyal ağlardan her saniye akmakta olan yüksek miktarda verinin işlenmesi ve belli bağlamlara oturtularak işlenmesi sosyal medyanın bir diğer özelliği olan hız ile tezat teşkil etmektedir. Bu durum beraberinde, kaçınılmaz olarak, yüzeyselliği getirmektedir. Katılımcılık ve dolayısıyla merkezsizlik ise görünüşte daha demokratik bir kamusal alan yanılgisı yaratmakta fakat esas olarak bilginin bağlamını ve hakikatini anlamsız hale getirmektedir. Böyle bir araç (medium) kaçınılmaz olarak büyük anlatıları komik duruma düşürecek eğlenceyi amaç haline getirecektir.

Görüntünün hızla aktığı sosyal medya epistemolojisinde haber değeri ve değer kavramı tıpkı hakikat kavramı gibi sosyal medyanın epistemolojisine bağlı olarak belirlenmektedir. Konvansiyonel medyanın $5 \mathrm{n} 1 \mathrm{k}$ kuralı sosyal medya ile yıkıma uğramış ve haber değeri ilginç, olağan dışı ve eğlenceli olana indirgenmiştir. Mobese kameralarından derlenen kaza görüntüleri veya yaramaz kedi videoları bağlamından koparılmış sadece sıra dışı veya eğlencelik olma özelliğine sahip haberler olarak haber bültenlerinde bile yer almaktadır. Çoğaltılması mümkün olan bu örneklerin 
doğruluğu veya yanlışlı̆̆ı, gerçekliği veya çarpıtma olması söz konusu değildir. Esas mesele hakikate ilişkin bir tartışmanın veya hakikat arayışı ve arzusunun sosyal medyanın yapısı içerisinde mümkün olmamasıdır.

\section{Sonuç}

$\mathrm{Bu}$ çalışma üç temel iddia üzerine oturmaktadır. Birincisi Oxford Dictionary'nin yaptığı post-truth tanımı hem çelişkilidir hem de açıklayıcı olmaktan uzaktır. Dolayısıyla yeni bir tanım yapmak gereklidir. İkincisi her iletişim aracının (medium) bir epistemolojisi ve hakikati tanımlama biçimi vardır. Üçüncüsü sosyal medya epistemolojisi hakikati çarpıtmaktan ziyade hakikat arzusunu öldürmekte olduğu için post-truth kavramı bu bağlamda tanımlanmalıdır.

Post-truth kelimesi Raph Keyes tarafından 2004 yılında kavramsallaştırılmaya çalışılmış olsa da asıl popülaritesini 2016'da yılın kelimesi seçilmesinden sonra kazanmıştır. Kavram özellikle ABD başkanlık seçimleri ve Brexit referandumuna üstü kapalı bir atıfla ele alınmıştır. Ancak kamuoyunun nesnel olgulardan ziyade kişisel duygu ve inançlar tarafından belirlenmesi şeklindeki tanımlama iki noktada problemli gözükmektedir. Birincisi post-truth dönemin ne zaman başladığına dair bir bilginin tanımda yer almamasıdır. Bir dönemleştirme söz konusu olmadığ için post-truth çağ, kamuoyunun nesnel olgularla belirlenmediği bütün zamanları kapsayacak şekilde genişletilebilir. Bu durumun anakronizme ve muğlaklığa yol açacağı ortadadır. İkinci problem sosyal medyaya üstü kapalı olarak atıf yapıldığ halde tanımda sosyal medyaya yer verilmemesidir. Zira post-truth hakkındaki bütün akademik çalışmalar sosyal medya üzerine odaklanmaktadır. Ne var ki yalan haber, çarpıtma ve manipülasyon sosyal medyanın ortaya çıkışından önce var olduğu gibi sosyal medyada da varlığını sürdürmektedir. O halde yeni bir dönemi tanımlamak için ortaya atılmış olan böyle bir kavramın kendisinden önceki dönemlerden nasıl bir farklılığı tanımladığını açık şekilde ortaya koymak gerekmektedir.

İletişim araçlarının kendi yapılarından kaynaklanan bir hakikati tanımlama biçimleri olduğu tezi teknolojik determinist olarak kabul edilen teorisyenlerin ortak iddiasıdır. Sözlü kültürlerde söz üzerinden tanımlanan bir hakikat tanımlaması varken basılı sözün (matbaanın) hakim olduğu dönemde kitabın yapısından kaynaklanan farklı bir epistemoloji ve hakikati tanımlama biçimi söz konusudur. Elektronik çağ ise yine elektronik ağların sahip olduğu epistemoloji doğrultusunda kendi zihin dünyasını inşa etmiştir. Gutenberg'in dünyasından Markoni’nin dünyasına, kağıdın egemenliğinden elektronik ağların egemenliğine geçiş esasında modernizmden postmodernizme geçişle paralel olmuştur. Daha doğru bir ifade ile değişen medya hakikat tanımlamasını da belirleyerek postmodern değerleri ortaya çıkarmıştır. Dolayısıyla post-truth kavramı postmodernizmden ve elektronik ağların epistemolojisinden bağımsız olarak ele alınamaz.

Post-truth kavramı, yalan haber, çarpitma veya kamuoyunun irrasyonel kararlar alması için yönlendirilmesi gibi tanımlamalarla açıklanamaz. Post-truth çağ hakikati arama veya gerçeği öğrenme arzusunun gereksiz hale geldiği, önemsizleştiği, zihinlerden silindiği ve sürekli akış halinde olan devasa boyuttaki veriler arasında 
hakikati aramanın imkânsızlaştığı bir çağ olarak tanımlanmalıdır. Bu tanımlama postmodernizmin büyük anlatıları yıkan, "küçük olanın güzelliğini" vurgulayan, ciddi ve ağır düşüncenin yerine eğlenceyi ve şenliği geçiren tavrı ile örtüşmektedir.

\section{Kaynakça}

Altun, Fahrettin. “M.McLuhanveJ.Baudrillard'ın Medya Kuramlarının Karşılaştırmalı Çözümlemesi”. Yayınlanmamış Doktora Tezi, İstanbul Üniversitesi SBE., 2006.

Baudrillard, Jean. Amerika. İstanbul: Ayrıntı Yayınları, 2006.

Baudrillard, Jean. Simülasyon ve Simulakrlar. Ankara: Doğu Batı Yayınları, 2011.

Bellah, Robert Neelly. "What is Axial About the Axial Age?". European Journal of Sociology, 46/1 (2005): 69-89.

Bolay, Süleyman Hayri. "Postmodernizm”. Moderniteden Postmoderniteye Değişim. Der., Coşkun Can Aktan. Konya: Çizgi Kitabevi, 2003.

Cevizci, Ahmet. Felsefeye Giriş. İstanbul: Say Yayınları, 2012.

Channel 4 News. "Cambridge Analytica Uncovered: Secret Filming Reveals Election Tricks". Erişim 19 Mart 2018. https://www.youtube.com/ watch? $\mathrm{v}=$ mpbeOCKZFfQ.

Debord, Guy. Gösteri Toplumu. İstanbul: Ayrıntı Yayınları, 2012.

İbni Haldun. Mukaddime cilt I. Ankara: Onur Yayınları, 1977.

İnnis, Harold. İmparatorluk ve İletişim Araçları. Ankara: Ütopya Yayınları, 2007.

İpek, Z. T. Işıl. “Risk Toplumunda Seçimler”. Sosyoekonomi, $26 / 36$ (2018): 65-79.

Jensen, Klaus Bruhn. "Nitel Bilim Olarak Beşeri Araştırmalar: Kitle İletişi̇m Araçlarına Katkılar”. Medya ve İzleyici. Der., Şahinde Yavuz. Ankara: Vadi Yayınları, 2005.

Kalın, İbrahim. Akıl ve Erdem. İstanbul: Küre Yayınları, 2013.

Kaplan, Hasan. "Psikanaliz Kuramının Yükselen Hermenötik Değeri". Dini Araştırmalar Dergisi, 11/31 (2008): 159-171.

Karagöz, Kezban. "Post-truth Çağında Yayıncilığın Geleceği". TRT Akademi Dergsisi, 3/6 (2018): 678-708.

Keyes, Ralph. Hakikat Sonrası Çağ. İzmir: Deli Dolu Yayınları, 2017.

Lyotard, Jean-François. Postmodern Durum. Ankara: Vadi Yayınları, 1994.

Mcluhan, Marshall. Gutenberg Galaksisi. İstanbul: Cogito, 2017.

Ong, Walter. Sözlü ve Yazılı Kültür. İstanbul: Metis Yayınları, 2013.

Oxford Living Dictionaries. "Post-truth." Erişim 19 Mart 2018. https:// en.oxforddictionaries.com/definition/post-truth

Özcan, Mesut. "Öznenin Ölümü: Post-truth Çağında Güvenlik ve Türkiye”. İNSAMER, (Ocak 2018): 1-12.

Postman, Neil. Televizyon: Öldüren Eğlence. İstanbul: Ayrıntı yayınları, 2012.

Ryan, Michael ve Douglas Kellner. Politik Kamera. İstanbul: Ayrıntı Yayınları, 2011.

Sunar, İlkay. Düşün ve Toplum. Ankara: Kültür Bakanlığı Yayınları, 1979.

Şendeniz, Özlem. “Kapitalizm ve Ağız Kokusu: 1920'li Yıllarda Toplumsal Cinsiyet Rollerini Listerine Reklamları Üzerinden İzlemek”. Fe Dergi, 10/2 (2018): 98- 
110.

Şener, Orhan. "Filtre Balonu Patlıyor mu: Guardian'dan Sağcı Yazar Açlımı”. 20 Şubat 2017 https://journo.com.tr/filtre-balonu-patliyor-mu?

Şimşek, Volkan. "Post-truth ve Yeni Medya: Sosyal Medya Grupları Üzerinden Bir İnceleme”. Global Media Journal TR Edition, 8/16 (2018)

Ünal, Recep ve Ahmet Taylan. "Sağlık İletişiminde Yalan Haber-Yanlış Enformasyon Sorunu ve Doğrulama Platformları”. Atatürk İletişim Dergisi, 14 (2017): 81-100.

Yanık, Aybars. "Popülizm (V): Post-truth”. Birikim Dergisi. 11 Ağustos 2017. http:// www.birikimdergisi.com/haftalik/8463/populizm-v-post-truth\#.XIBWvgzZPY.

Yüksel, Erkan. İletişim Kuramları. Eskişehir: Anadolu Üniversitesi Yayınları, 2013. 
İNSAN\&İNSAN, Yıl/Year 7, Sayı/Issue 23, Kış/Winter 2020, 20-36

DOI: https://doi.org/10.29224/insanveinsan.577956

\title{
Post-Truth as the Loss of the Truth: A Conceptualization Attempt
}

\author{
AHMET GÜVEN
}

Abstract: The major transformation in the structure of mass media has brought about ethical debates. The post-truth concept, which has come to the fore frequently in recent years, is at the center of these discussions. According to the Oxford Dictionary's definition, post-truth, which means that public opinion is defined by personal feelings and beliefs rather than objective facts, has become a concept that academic studies have also focused on. The concept, which is dealt with in the context of more fake news, distortion of reality and making the public irrational choices in this way, seems to be problematic.

The basic claim of this study is that the concept of post-truth cannot be defined as the manipulating of public opinion by fake and distorted news. In this context, the conceptual discussion constitutes the method of the study. The technological determinist approach, which claims that the medium determines the truth perception of the age, constitutes the theoretical basis of the debate. The result obtained from the discussion is that postmodernism's attitude which rejects the existence of truth stems from the structure of electronic media and that the concept of post-truth should be defined as loss of truth, not as a distortion of truth in this context.

Key Words: Post-truth, Postmodernism, Technological determinism, Social media, Loss of the truth. 